\title{
Conscious sedation for awake fibreoptic intubation: a review of the literature
}

\section{La sédation consciente pour l'intubation fibroscopique vigile : revue de la littérature}

\author{
Kevin D. Johnston, MBChB (Hons) • \\ Mridula R. Rai, MD
}

Received: 1 November 2012/ Accepted: 5 March 2013/Published online: 20 March 2013

(C) Canadian Anesthesiologists' Society 2013

\begin{abstract}
Purpose Awake fibreoptic intubation (AFOI) is the gold standard of management of the predicted difficult airway. Sedation is frequently used to make the process more tolerable to patients. It is not always easy to strike a balance between patient comfort and good intubating conditions on the one hand and maintaining ventilation and a patent airway on the other. In the last 30 years, many drugs and drug combinations have been described, but there is very little in the literature to help guide the practitioner to choose between them. The objective of this article is to discuss the evidence supporting the use of the agents described with regard to their efficacy, recommended doses and techniques, and limitations to their use for AFOI.

Source Publication databases were searched for articles published from 1996 to 2012 relating to sedation for AFOI. Principle findings Benzodiazepines, propofol, opioids, alpha $_{2}$-adrenoceptor agonists, and ketamine are the main classes of drugs that have been described to facilitate AFOI. Drugs that are most suitable have a combination of

Author contributions Kevin Johnston was responsible for the conception of the review. Kevin Johnston and Mridula Rai contributed substantially to the design of the article and the acquisition of data, and they were involved in the critical revision of the article.
\end{abstract}

\footnotetext{
K. D. Johnston, MBChB (Hons) ( $\square)$

Department of Anesthesia, Leeds General Infirmary,

Great George Street, Leeds LS1 3EX, UK

e-mail: kevindjohnston@googlemail.com
}

K. D. Johnston, MBChB (Hons)

School of Medicine, The University of Leeds, Leeds, UK

M. R. Rai, MD

Nuffield Department of Anesthetics, John Radcliffe Hospital,

Oxford, UK both anxiolytic and analgesic properties. The ideal choice of drug may vary depending on the patient and the indication for AFOI.

Conclusion There is good evidence to support the use of two drugs in particular, remifentanil and dexmedetomidine. Each has certain unique characteristics that make them an attractive choice for an AFOI.

\section{Résumé}

Objectif L'intubation fibroscopique vigile (AFOI pour l'acronyme anglais) constitue l'étalon or de la prise en charge de voies aériennes anticipées comme étant difficiles. La sédation est fréquemment utilisée pour rendre le processus plus tolérable pour les patients. Il n'est pas toujours facile de trouver un bon équilibre entre le confort du patient et de bonnes conditions d'une part, et le maintien de la ventilation et de la perméabilité des voies aériennes d'autre part. Au cours des 30 dernières années, de nombreux médicaments et combinaisons de médicaments ont été décrits, mais la littérature ne contient que très peu d'exemples pour guider le praticien dans le choix du bon médicament ou de la bonne combinaison médicamenteuse. L'objectif de cet article est de présenter les données probantes appuyant l'utilisation des agents décrits en ce qui touche à leur efficacité, aux doses et techniques recommandées, et aux limites de leur utilisation lors d'intubation fibroscopique vigile.

Source Nous avons mené une recherche dans les bases de données de publication afin d'extraire les articles publiés entre 1996 et 2012 concernant la sédation pour l'AFOI.

Constatations principales Les benzodiazépines, le propofol, les opioïles, les agonistes des adrénocepteurs alpha-2 et la kétamine sont les principales classes de médicaments qui ont été décrites pour faciliter l'AFOI. Les 
médicaments les plus adaptés à cet usage possèdent une combinaison de propriétés anxiolytiques et analgésiques. Le médicament de choix peut varier selon le patient et l'indication pour l'AFOI.

Conclusion Des données probantes convaincantes appuient l'utilisation de deux médicaments en particulier, le rémifentanil et la dexmédétomidine. Chacun de ces médicaments possède certaines caractéristiques spécifiques qui le rendent intéressant pour réaliser une AFOI.

Awake fibreoptic intubation (AFOI) is the gold standard of management of patients with an anticipated difficult airway. It can be an unpleasant experience even with careful and meticulous application of local anesthetic. Conscious sedation is desirable not only to make the procedure more tolerable for patients but also to ensure optimal intubating conditions, particularly in the presence of abnormal laryngeal anatomy and pathology. Deep sedation can result in loss of airway with serious consequences. A major challenge during AFOI is to provide adequate sedation while maintaining a patent airway and ensuring spontaneous ventilation.

The ideal sedative for AFOI would provide anxiolysis and a degree of amnesia with a low incidence of recall of the procedure. It would have analgesic properties, suppress the cough and gag reflex, and be safe and easy to titrate with minimal respiratory and cardiovascular side effects. In the last three decades, the use of several classes of drugs have been described, from benzodiazepines (e.g., diazepam and midazolam), to opioids (e.g., morphine, fentanyl, and more recently remifentanil), to alpha ${ }_{2}$ agonists (e.g., clonidine and dexmedetomidine), and to intravenous induction agents (e.g.,ketamine and propofol). The purpose of this article is to review the evidence supporting the use of currently available drugs with specific reference to their efficacy, safety profile, drug dosages, and limitations when used for an AFOI.

\section{Methods}

A search was made of PubMed-MEDLINE, Google Scholar, EMBASE, the Cochrane Library, and the Web sites of seven peer-reviewed anesthetic journals (1996-May 2012) using the terms: "fibreoptic intubation", "awake fibreoptic", "awake intubation", "conscious sedation", "remifentanil", "fentanyl”, "sufentanil", "morphine", "midazolam", "propofol”, "ketamine", "dexmedetomidine", and "clonidine". The full texts of articles identified from potentially relevant titles and abstracts were reviewed. Both authors independently screened the retrieved reports and excluded irrelevant data. A manual inspection was subsequently performed through the reference
Table 1 Scottish Intercollegiate Guidelines Network (SIGN) Guidelines Levels of evidence

1 High quality meta-analyses, systematic reviews of RCTs, or RCTs with a very low risk of bias $(1++)$

Well-conducted meta-analyses, systematic reviews, or RCTs with a low risk of bias $(1+)$

Meta-analyses, systematic reviews, or RCTs with high risk of bias $(1-)$

2 High quality systematic reviews of case control or cohort studies

High quality case control or cohort studies with a very low risk of confounding or bias and a high probability that the relationship is causal $(2++)$

Well-conducted case control or cohort studies with a low risk of confounding or bias and a moderate probability that the relationship is causal $(2+)$

Case control or cohort studies with a high risk of confounding or bias and a significant risk that the relationship is not causal (2-)

3 Non-analytic studies, e.g., case reports, case series

4 Expert opinion

$\mathrm{RCTs}=$ randomized controlled trials

lists of all studies, and foreign language articles with an English language abstract were included. We included all randomized controlled trials (RCTs), clinical trials, and case reports comparing or describing drugs for sedation for AFOI. We excluded studies that described conscious sedation for bronchoscopy and other awake intubation techniques using devices such as the intubating laryngeal mask or video laryngoscopes. Most studies use a combination of two and occasionally even three drugs to achieve a desired state of conscious sedation. In these cases, there is usually a primary drug, and other drugs are used in conjunction to achieve a desired state. We classified the data according to the primary drug that was the focus of the clinical trial or the case reports. The strength of the available evidence was assessed according to the Scottish Intercollegiate Guidelines Network (Table 1) and summarized in Tables 2 and 3. We identified four drug types that have been used primarily for conscious sedation for AFOI, i.e., benzodiazepines, propofol, opioids, and alpha ${ }_{2}$ agonists. Following a discussion of the wider issues relating to the conduct and safety of sedation for AFOI in general, the evidence supporting the use of the most popular drugs and their respective combinations for this purpose is discussed.

\section{Principles of safe sedation for AFOI}

Drugs used for conscious sedation during AFOI generally fall into two categories. There are those that, by virtue of their anxiolytic properties, are used to supplement the psychological management of the patient. Though a good rapport with a well-prepared patient may help, it is not enough in most cases. Other drugs are used for their analgesic properties as adjuncts to local anesthesia (LA) and contribute to the 


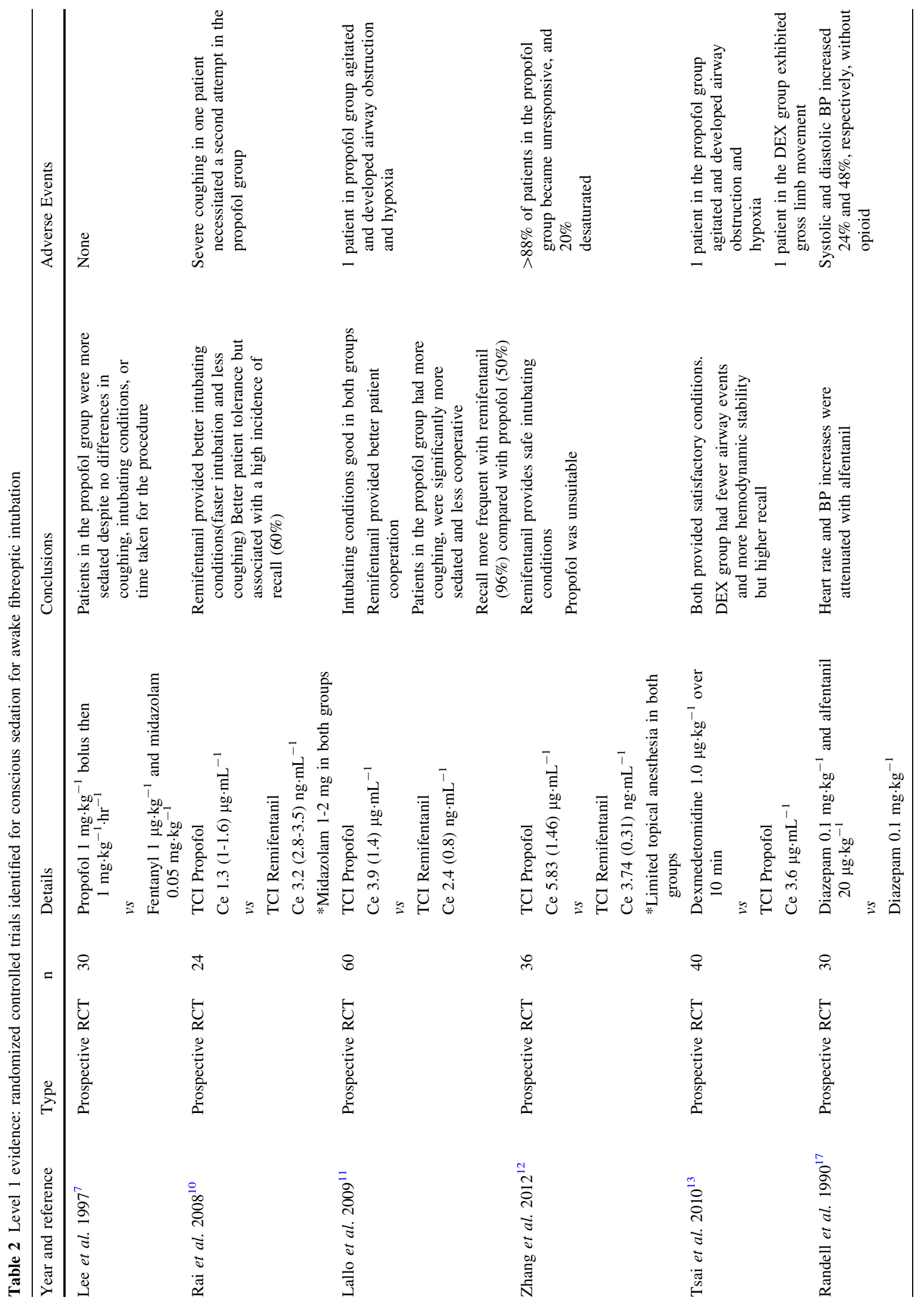




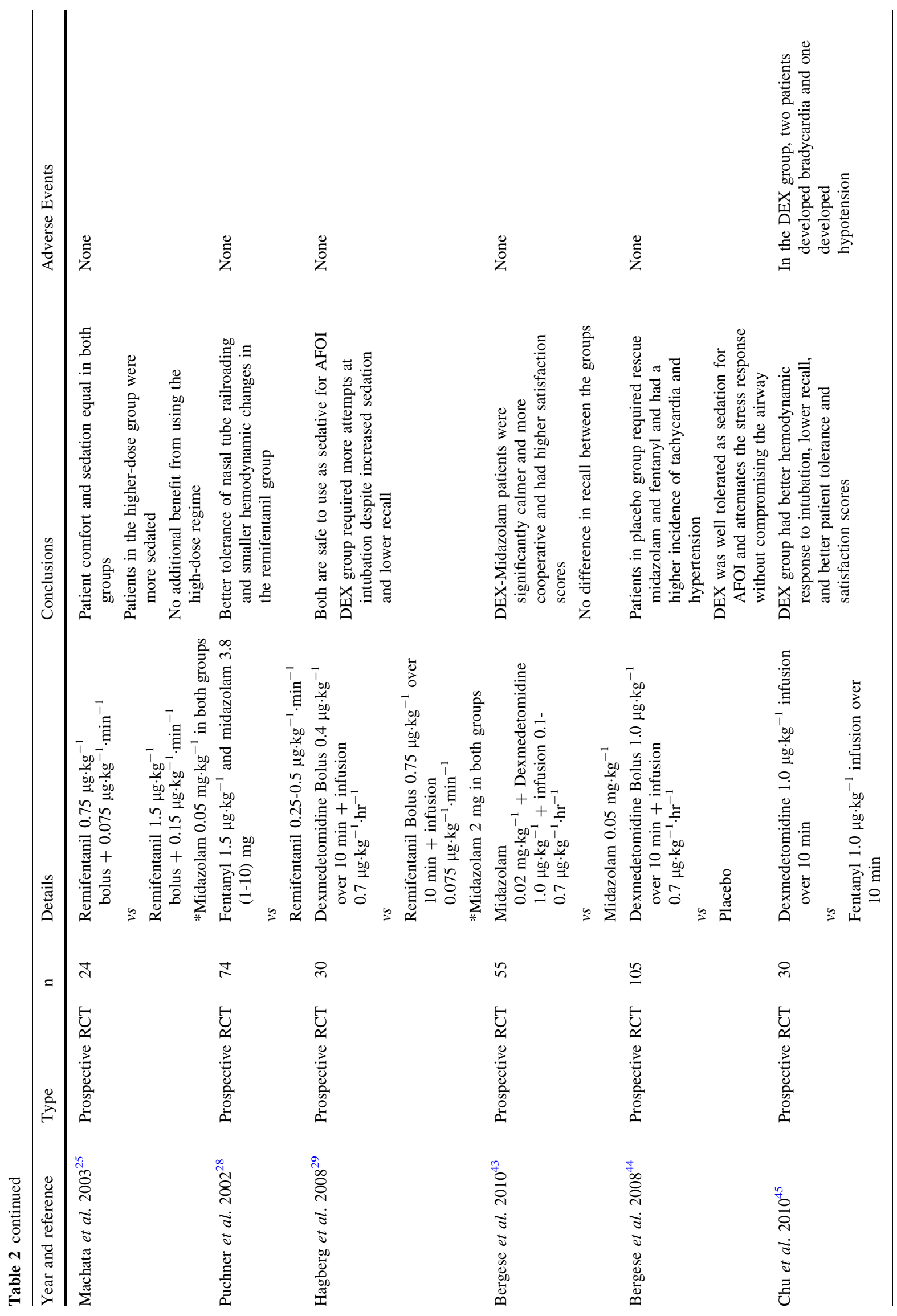




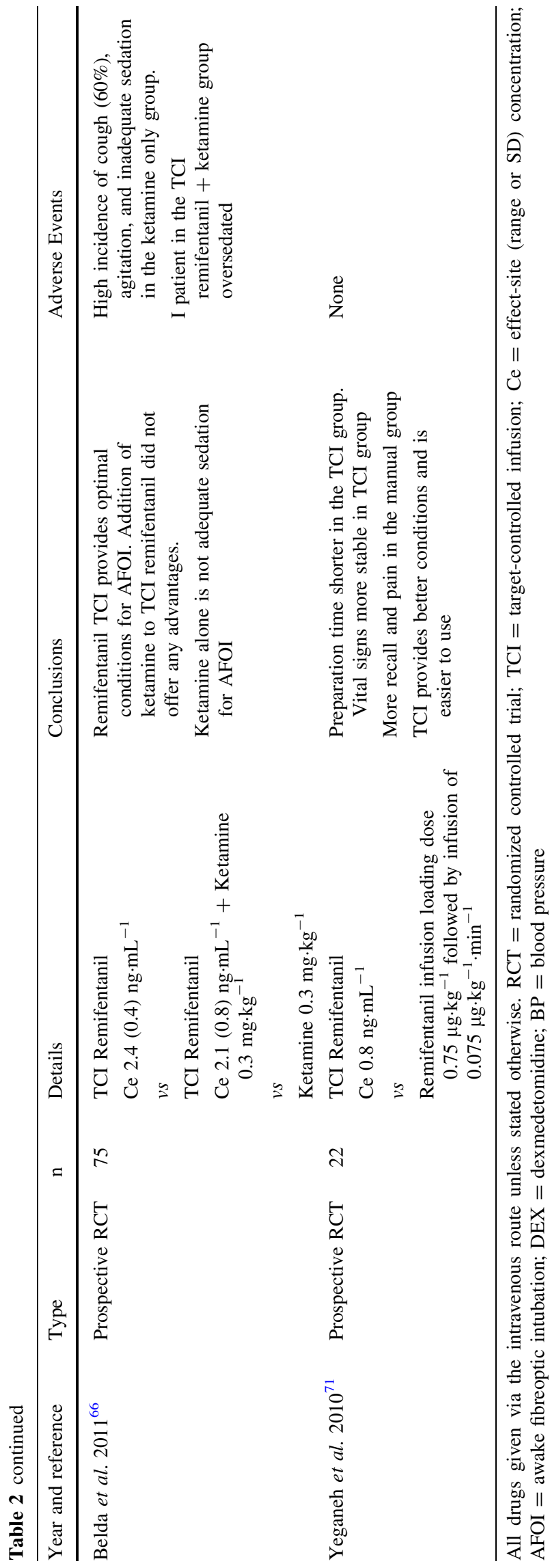

control of respiratory and hemodynamic responses to airway instrumentation. Though evidence is lacking and preferences tend to follow trends with time, some techniques of local anesthetic topicalization may be more effective and less demanding on pharmacological analgesia than others. Indeed, the quality of topicalization also draws significantly on operator experience as well as on the anatomical and physiological state of any particular patient and the urgency of the situation. The use of anxiolytic and analgesic properties in combination is the key to rational "sedation" for AFOI, although the relative requirements for each vary with the circumstances. For example, the conditions required for safe tracheal intubation of a patient in respiratory distress with an oropharyngeal mass are likely to be very different from those required for the management of a patient with a cervical spine injury in whom coughing and straining should be avoided. Individual drugs may have anxiolytic or analgesic properties or both. Unfortunately, many (but not all) anxiolytic drugs have hypnotic properties that tend to predispose to further loss of airway patency, while opioid analgesics cause respiratory suppression. It has thus often been stated that "sedation" should not be used to facilitate AFOI in patients at risk of airway obstruction or respiratory failure, although the emergence of newer therapies may challenge this view. Topicalization per se can be difficult and dangerous in severely anxious patients with impending airway obstruction. With these concerns in mind, measures are needed to optimize the safety of the procedure regardless of choice of drug. Appropriate levels of "sedation" for safe AFOI are difficult to standardize, not least because the required combination of anxiolysis and analgesia varies widely from case to case. Moreover, the clinical end points of optimal "sedation" using opioids cannot really be compared with the end points of "sedation" using drugs that are primarily hypnotic. Sedation scores and the use of depth-ofanesthesia monitoring (bispectral index, entropy) may be rational in the future, but, to date, they have been largely confined to trials. On the other hand, basic monitoring modalities (pulse oximetry, electrocardiogram, and noninvasive blood pressure) should be seen as mandatory.

\section{Benzodiazepines}

Studies using benzodiazepines as the primary sedative agent generally describe their use in combination with an opioid such as fentanyl or morphine. The two earliest and, to date, largest case series (totalling more than 600 patients) describing sedation for AFOI were published by Ovassapian in the early $1980 \mathrm{~s}^{1-2}$ Patients were premedicated with oral diazepam (5-10 mg) and/or intramuscular morphine (5$10 \mathrm{mg}$ ) and then administered intravenous diazepam and fentanyl (averaging $0.15 \mathrm{mg} \cdot \mathrm{kg}^{-1}$ and $1.5 \mu \mathrm{g} \cdot \mathrm{kg}^{-1}$, 


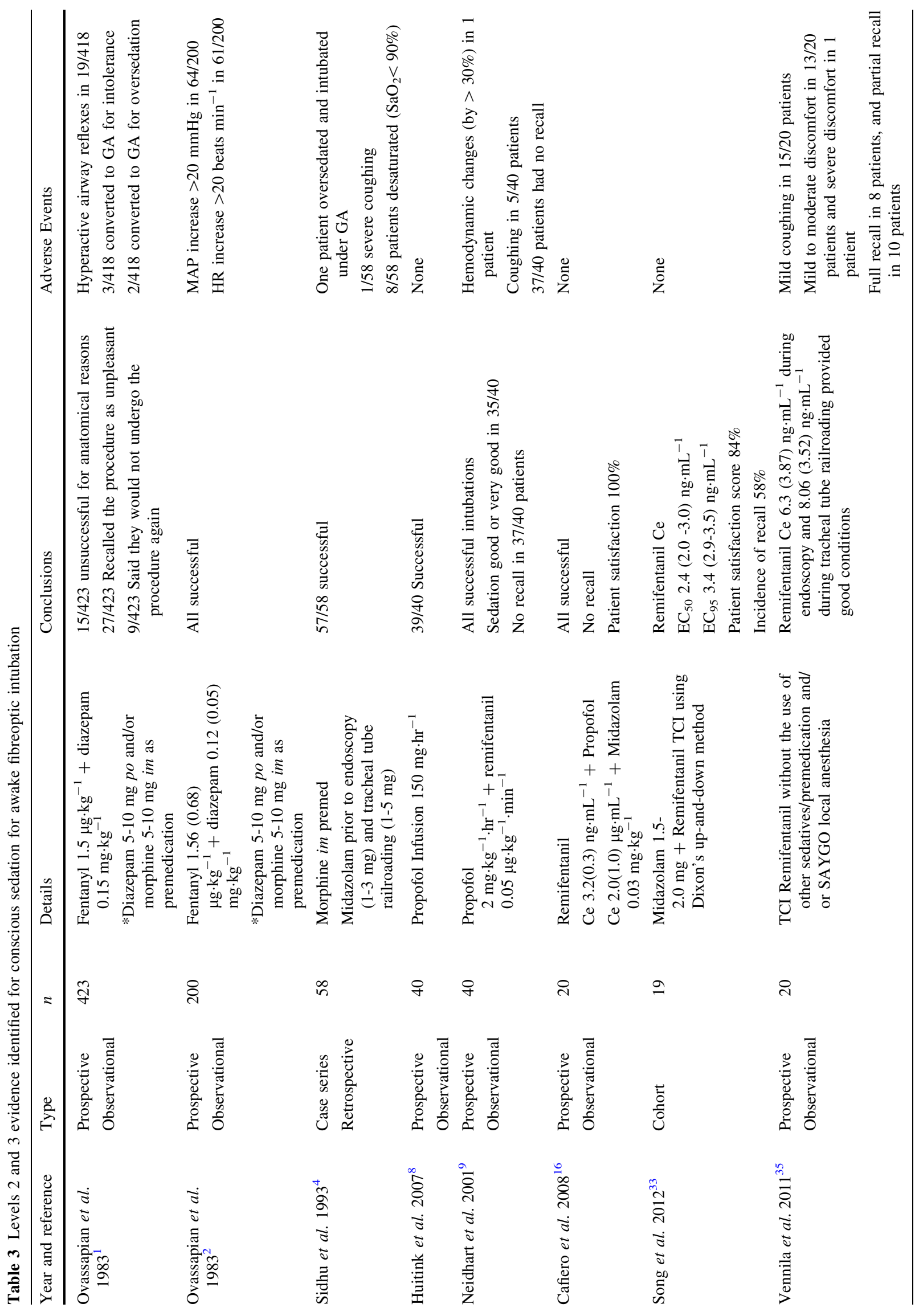




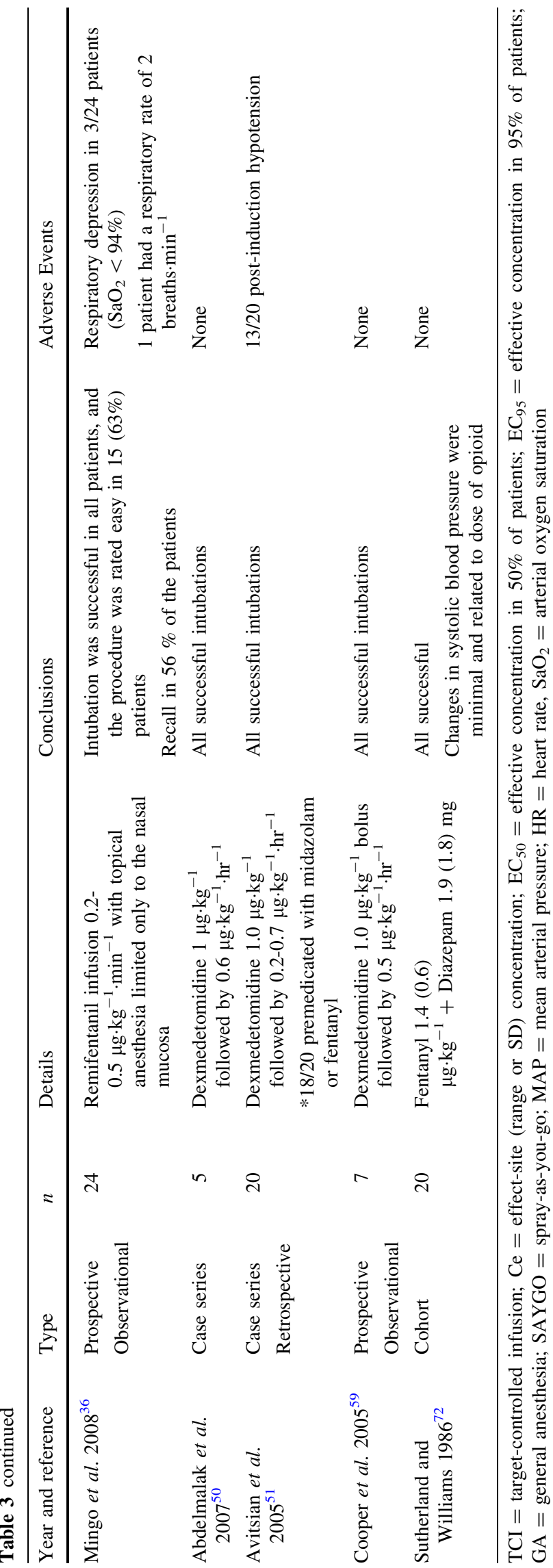

respectively). Six of the 413 patients in the first series did not receive any sedation, and five of these reported that they would "prefer not to go through the same procedure again"; only two of the patients became restless and/or uncooperative, indicating disinhibition or oversedation. ${ }^{1}$

In a later case series, Ovassapian used smaller doses of diazepam $\left(0.07 \mathrm{mg} \cdot \mathrm{kg}^{-1}\right)$ and slightly more fentanyl $\left(1.7 \mu \mathrm{g} \cdot \mathrm{kg}^{-1}\right)$. One hundred twenty-nine patients who were at high risk of aspiration for various reasons were sedated until they were "lightly asleep if unstimulated, but still responsive to command and able to carry out instructions". None aspirated and there were no instances of airway obstruction, but two patients required "verbal encouragement to breathe". ${ }^{3}$ Despite the impressive size of these case series, it is impossible to comment on the safety of this combination of drugs in any one individual or even groups of similar individuals Nevertheless, the overall data seem to suggest it was a safe technique, albeit obviously in expert hands. It is also worth mentioning that these series date from a time when pulse oximetry may not have been universally used. Indeed, data on oxygen saturation during AFOI is not provided in the above work.

Midazolam subsequently supplanted diazepam as the benzodiazepine of choice in combination with fentanyl. Sidhu et al. administered intravenous midazolam (1-3 mg during endoscopy and 1-5 mg during tracheal tube railroading) to 58 patients needing AFOI for C-spine surgery who were premedicated with intramuscular morphine. ${ }^{4}$ Topicalization was with "spray-as-you-go" (SAYGO) LA, and by definition, the patients would have had otherwise normal airway anatomy and no respiratory distress. The mean time to intubation was $16 \mathrm{~min}$. Fourteen percent of patients desaturated to $<90 \%$, yet moderate to severe coughing occurred in $20 \%$, and in one patient, tracheal intubation necessitated general anesthesia. These observations would suggest that the use of high doses of midazolam may not be able to compensate for inadequate analgesia or topicalization and may be associated with respiratory compromise.

Interestingly, when Reasoner et al. compared topical anesthesia (SAYGO) with nerve blockade (glossopharyngeal and superior laryngeal) for AFOI in patients undergoing cervical spine surgery, they used a mean of $2.7 \mathrm{mg}$ of midazolam and $44 \mu \mathrm{g}$ of fentanyl in the former group and $3.2 \mathrm{mg}$ and $66 \mu \mathrm{g}$, respectively, in the latter group. ${ }^{5}$ All 40 patients remained sufficiently awake to cooperate with neurological examination, but four patients desaturated to $<90 \%$. In another study, Joo et al. used higher doses (mean $4 \mathrm{mg}$ midazolam and $75 \mu \mathrm{g}$ fentanyl) in 18 patients with a suspected difficult tracheal intubation. Awake fibreoptic intubation took a mean of $16 \mathrm{~min}$, and two patients $(11 \%)$ desaturated to $<90 \%{ }^{6}{ }^{6}$

It is difficult to arrive at any conclusion on the use of benzodiazepines for AFOI based on the small number of 
studies available. The advantage of the technique lies in its simplicity and the wide availability and long-standing experience with use of both classes of drugs; however, the apparent disadvantage is that use of intermittent boluses of drugs can be associated with overshoot and the risk of oversedation.

\section{Propofol}

Descriptions of the use of propofol by simple bolus or infusion for AFOI are surprisingly sparse and we identified three studies. The best available evidence is provided by Lee et al. who randomized 30 patients to receive either propofol $\left(1 \mathrm{mg} \cdot \mathrm{kg}^{-1}\right.$ followed by $\left.1 \mathrm{mg} \cdot \mathrm{kg}^{-1} \cdot \mathrm{hr}^{-1}\right)$ or the combination of midazolam $\left(0.05 \mathrm{mg} \cdot \mathrm{kg}^{-1}\right)$ and fentanyl $\left(1 \mu \mathrm{g} \cdot \mathrm{kg}^{-1}\right){ }^{7}$ There were no significant differences in intubating conditions, coughing, or time taken for the procedure, but patients in the propofol group were more sedated. More recently, Huitink et al. published a case series of 40 patients receiving propofol at a fixed rate of $150 \mathrm{mg} \cdot \mathrm{hr}^{-1}$ and LA achieved by a standard SAYGO technique. There were "no complications" associated with the technique; however, the authors didn't specifically report respiratory observations. ${ }^{8}$ Neidhart et al. combined a fixed rate infusion of propofol $\left(2 \mathrm{mg} \cdot \mathrm{kg}^{-1} \cdot \mathrm{hr}^{-1}\right)$ with remifentanil $\left(0.05 \mu \mathrm{g} \cdot \mathrm{kg}^{-1} \cdot \mathrm{min}^{-1}\right)$. Sedation was rated as "good to very good" in 35/40 patients whose tracheas were all intubated successfully. No patient became hypoxic, and the heart rate and blood pressure remained within $30 \%$ of baseline in all but one. ${ }^{9}$

A greater body of published work has focused on targetcontrolled infusion (TCI) of propofol for AFOI, either as the sole agent or in combination with remifentanil. ${ }^{10-13}$ Targetcontrolled infusions of propofol for AFOI have been assessed in three RCTs providing level 1 evidence comparing it with remifentanil (Table 2) ${ }^{10-12}$ and in one RCT comparing it with dexmedetomidine ${ }^{13}$ In the propofol arm of the randomized trial by Rai et al., the tracheas of 9/10 patients were successfully intubated at the first attempt after SAYGO topicalization. Severe coughing in one patient did necessitate a second attempt. ${ }^{10}$ The mean (range) propofol TCI in their study was $1.3(1-1.6) \mu \mathrm{g} \cdot \mathrm{mL}^{-1}$, which is lower than the effect-site concentrations reported in other studies. This may be due to the authors using 1-2 mg of midazolam in conjunction with TCI propofol to achieve the desired levels of sedation. The study reported better intubating conditions and patient tolerance in the remifentanil group, although the patient recall of the procedure was lower in the propofol group. In another study, Tsai et al. intubated the tracheas of $19 / 20$ patients at an average final propofol effect-site concentration of $3.6 \mu \mathrm{g} \cdot \mathrm{mL}^{-1}$. Spray-as-you-go topicalization was used in all their patients who had oral cancer and presumably irregular airway anatomy. Increasing the propofol to $5.0 \mu \mathrm{g} \cdot \mathrm{mL}^{-1}$ in one patient (because of movement) resulted in desaturation to $80 \%$. None recalled the tracheal intubation, but they were uncooperative at the end, and immediate progression to general anesthesia was necessary in every instance. ${ }^{13}$ Airway obstruction was more frequent with propofol than with dexmedetomidine, as was the increase in heart rate in response to tracheal intubation. An even higher average (standard deviation) propofol concentration of 3.9 (1.4) $\mu \mathrm{g} \cdot \mathrm{mL}^{-1}$ was used by Lallo et al. who successfully intubated the tracheas of 29/30 similarly topicalized patients. One case was abandoned for reasons similar to those reported by Tsai et al., yet moderate to severe coughing was still reported in $30 \%$ of patients, and patients in the propofol group were significantly more sedated and less cooperative than those in the remifentanil group. ${ }^{11}$ Zhang et al. compared the suitability of propofol and remifentanil as single agents for sedation for AFOI without the use of premedication or topicalization of the larynx with local anesthetic. ${ }^{12}$ Whereas intubation was possible at remifentanil effect-site concentrations little more than those required for objective signs of sedation, an average concentration of propofol of 5.8 (1.5) $\mu \mathrm{g} \cdot \mathrm{mL}^{-1}$ was necessary for passage of the tracheal tube through the vocal cords under these conditions. Fifteen of the 17 patients lost response to prodding and shaking, and severe respiratory depression occurred in one. The authors concluded that propofol is unsuitable for sedation if laryngeal topicalization is not used.

With regard to propofol, the above RCTs support the premise that the balance between underdosing (which may be associated with coughing and movement) and overdosing (with airway obstruction and loss of cooperation) can be difficult to achieve, and use of propofol for AFOI is associated with a low incidence of recall at the expense of an increased risk of oversedation. There is no clear consensus on the dose range; however, the risk of oversedation increases with effect-site concentrations higher than 3-3.5 $\mu \mathrm{g} \cdot \mathrm{mL}^{-1} \cdot{ }^{11-13}$

The concomitant use of benzodiazepines and /or opioids, such as fentanyl or remifentanil, may improve the efficacy of TCI propofol and help minimize the side effects. ${ }^{9,10,14-16}$

More recently, case reports have described the concurrent use of propofol TCI with remifentanil TCI for AFOI $^{14-16}$ Authors describing the combined use of TCI propofol and remifentanil for AFOI have reported mean effect-site concentrations during the procedure of 0.8 $2.0 \mu \mathrm{g} \cdot \mathrm{mL}^{-1}$ and $1.5-3.2 \mathrm{ng} \cdot \mathrm{mL}^{-1}$, respectively. Although there is no evidence supporting the superiority of TCI propofol over a fixed rate infusion in the setting of an AFOI, it is safe to say that a TCI has a more consistent pharmacodynamic effect and may allow for a more predictable level of sedation to be maintained. 


\section{Opioids}

Awake fibreoptic intubation can be associated with intense nociceptive stimulation, especially during passage of the tracheal tube through the nose and the larynx. While pure sedatives provide anxiolysis and amnesia and may help to smooth the process, they cannot substitute for inadequate airway topicalization with local anesthetic. Opioids are strong analgesics with some hypnotic effect and can help attenuate the coughing and hemodynamic changes resulting from airway instrumentation. Indeed, on occasions such as in the presence of mucosal inflammation, difficult anatomy, or excessive secretions, local anesthetic alone may be inadequate to eliminate the airway responses to instrumentation.

At one time or another, most opioids in common use have been used as adjuncts to sedation for AFOI. Prior to the introduction of remifentanil, incremental boluses of fentanyl or occasionally alfentanil, usually in combination with a benzodiazepine, such as diazepam or midazolam, were used most frequently ${ }^{1-3,5,6,17}$ Nevertheless, boluses of opioids with midazolam for sedation can be associated with significant hypoxemia $\left(\mathrm{SaO}_{2}<90 \%\right)$, apnea, and even aspiration. ${ }^{18,19}$ Opioids have also been used as premedication by either the oral or intramuscular route, the latter most commonly morphine $5-10 \mathrm{mg} .{ }^{1-4}$

\section{Remifentanil}

Remifentanil is a potent and ultra-short-acting opioid with a context-sensitive half-time of three minutes and an elimination half-time of six minutes. Its unique pharmacokinetic characteristics make it easy to titrate, while it provides profound analgesia, suppresses airway reflexes, and has minimal effect on cognitive function. ${ }^{20-24}$ This makes it an attractive drug of choice for the intensely stimulating but usually brief airway manipulation during an AFOI. It is increasingly being used either as the primary agent or in conjunction with midazolam ${ }^{10,11,25}$ and, more recently, propofol ${ }^{14-16}$ to provide sedation during AFOI.

Studies evaluating remifentanil as a primary agent have described its use at different set rates of infusion, by bolus dose followed by infusion, and, more recently as a TCI.

Reusche and Egan provided one of the earliest descriptions in 1999. They used an infusion of $0.175 \mu \mathrm{g} \cdot \mathrm{kg}^{-1} \cdot \mathrm{min}^{-1}$ (combined with midazolam $2 \mathrm{mg}$ and droperidol $0.625 \mathrm{mg}$ ) in a patient with Ludwig's angina. ${ }^{26}$ The authors described suspending the remifentanil at a predicted effect-site concentration of $4 \mathrm{ng} \cdot \mathrm{mL}^{-1}$ when the patient appeared "too sedated", although they didn't expand on the circumstances which led to this intervention. Their patient had no memory of the procedure, which not being characteristic of remifentanil, suggests that the effects of the other drugs were significant and may have largely contributed to the oversedation.

With these concerns in mind, Puchner et al. described the use of remifentanil at a rate of $0.07 \mu \mathrm{g} \cdot \mathrm{kg}^{-1} \cdot \mathrm{min}^{-1}$ with no additional sedative drug to achieve AFOI in a morbidly obese patient with respiratory failure. ${ }^{27}$ Other than respiratory depression, which responded to commands to breathe, no airway loss was reported per se. The authors went on to randomize a further 74 patients requiring nasal intubation for elective maxillofacial surgery to undergo an AFOI with either a relatively high dose of remifentanil (0.25-0.5 $\mu \mathrm{g} \cdot \mathrm{kg}^{-1} \cdot \mathrm{min}^{-1}$, as required) or boluses of fentanyl and midazolam. ${ }^{28}$ Hemodynamic changes were lower and tolerance of the procedure was higher in the remifentanil group. Unsurprisingly, respiratory depression was very common, but even at these doses, was always corrected by verbal commands to breathe.

In an attempt to find the optimal dose of remifentanil, Machata et al. randomized 24 patients requiring AFOI to a "lower" or "higher" dose of remifentanil $\left(0.75 \mu \mathrm{g} \cdot \mathrm{kg}^{-1}\right.$ bolus followed by $0.075 \mu \mathrm{g} \cdot \mathrm{kg}^{-1} \cdot \mathrm{min}^{-1}$ vs $1.5 \mu \mathrm{g} \cdot \mathrm{kg}^{-1}$ bolus followed by $0.15 \mu \mathrm{g} \cdot \mathrm{kg}^{-1} \cdot \mathrm{min}^{-1}$, respectively). Patients in the "higher" dose group coughed less and had reduced recall, but they had more respiratory depression and no advantage in terms of better hemodynamic stability or patient tolerance of the procedure. ${ }^{25}$ Airway control was not lost in any patient and midazolam $\left(0.05 \mathrm{mg} \cdot \mathrm{kg}^{-1}\right)$ was administered to both groups. The authors recommended the lower dose regime, which was subsequently used by Hagberg et al. in their double-blind trial randomizing 30 patients needing AFOI to receive either remifentanil or dexmedetomidine. ${ }^{29}$

Machata et al. did not report the length of time taken for tracheal intubation in their patients; therefore, little can be said about the likely effect-site concentrations of remifentanil being compared in their study. Simple dosage regimens based only on patient weight do not result in stable effect-site concentrations because of the complex pharmacokinetics of drugs such as propofol and remifentanil. Manual administration is therefore more likely to be associated with overshoot, interpatient variability, and accumulation. Also, patient tolerance during fibreoptic intubation using these regimens is highly dependent on the delay between the onset of the infusion and the beginning of the procedure, and it also varies with the duration of fibreoptic intubation. There is evidence to suggest that remifentanil sedation administered via TCI provides better conditions and is associated with a lower incidence of complications, such as apnea and respiratory depression, compared with manual administration. ${ }^{30-32}$ By using TCI, stable effect-site concentrations can be obtained rapidly and maintained for as long as desired, since these devices 
deliver intravenous drugs using a computer-controlled algorithm that takes into account the drug's particular pharmacokinetic properties. Target-controlled infusion allows the user to achieve a chosen predicted concentration rapidly and with minimal overshoot.

As the principle agent for sedation, TCI remifentanil has thus far been compared with TCI propofol for AFOI in three well-designed RCTs. Rai et al. randomized 24 patients requiring AFOI for elective surgery to TCI remifentanil or propofol, both titrated initially to a modified Steward sedation score. Tracheal intubation with a mean effect-site concentration of remifentanil of $3.2(2.8-3.5) \mathrm{ng} \cdot \mathrm{mL}^{-1}$ was faster, rated easier by the operator, and better tolerated by patients than tracheal intubation with a mean effect-site concentration of propofol of $1.3(1-1.6) \mu \mathrm{g} \cdot \mathrm{mL}^{-1} .{ }^{10}$ The authors attributed the improved conditions in the remifentanil group to the antitussive and analgesic properties of remifentanil, which resulted in reduced coughing and tracheal tube tolerance during intubation. Lallo et al. randomized 60 patients to either TCI remifentanil or TCI propofol, both of which were titrated to the patients' comfort during the procedure and not to a sedation score. ${ }^{11}$ Intubating conditions were found to be satisfactory in both groups; however, all patients receiving remifentanil (mean effectsite concentration $2.4 \mathrm{ng} \cdot \mathrm{mL}^{-1}$ ) were able to open their eyes and breathe on command if saturations fell, which was not the case with those receiving propofol (mean effect-site concentration $3.9 \mu \mathrm{g} \cdot \mathrm{mL}^{-1}$ ). The only procedure abandoned secondary to loss of the airway was in the propofol group. Patients in the propofol group were more sedated and, not surprisingly, had a lower incidence of recall compared with those in the remifentanil group. The authors commented that the opioid would therefore be their choice of agent in situations where manual ventilation might be difficult. More recently, Zhang et al. have reported that an effect-site concentration of remifentanil 3.74 (0.31) $\mathrm{ng} \cdot \mathrm{mL}^{-1}$ was sufficient to allow AFOI without either premedication or laryngeal topicalization. ${ }^{12}$ All their patients responded to commands to breathe and sustained saturations $>90 \%$. Recall was $100 \%$ with remifentanil compared with $41 \%$ with propofol, but 15 of the 17 patients in the latter group became unresponsive, and three patients desaturated to $<90 \%$.

Song et al. attempted to determine the optimal dose and rate of delivery of remifentanil for AFOI by using Dixon's up-and-down method. The effect-site concentration of remifentanil to achieve AFOI without sustained or repetitive coughing in $95 \%$ of patients $\left(\mathrm{EC}_{95}\right)$ was reported to be $3.38 \mathrm{ng} \cdot \mathrm{mL}^{-1}$ (95\% confidence interval 2.9 to 3.46 ) when used in combination with midazolam (1.5-2.0 $\mathrm{mg} i v)$ and topical anesthesia. ${ }^{33}$

Results of studies that have looked at remifentanil as the primary agent for AFOI are generally in agreement that patients usually have a higher incidence of recall of the procedure. ${ }^{10-12,28,29}$ Use of remifentanil is associated with an incidence of recall of 50-100\% when used as a sole agent and even in high doses or when used in conjunction with midazolam. Although patients had a good recall of the event in all of the above studies, it is interesting to point out that they did not perceive the event to be an unpleasant experience, and they were not distressed by it. Use of higher doses of midazolam to reduce recall can potentiate the respiratory depressant effects of remifentanil. ${ }^{34}$ More recently, remifentanil has been used in combination with propofol in an attempt to reduce recall and minimize respiratory complications. ${ }^{14-16}$

Moerman et al. investigated the combination of TCI propofol with either TCI remifentanil or a manual infusion of remifentanil in 60 patients undergoing sedation for colonoscopy. ${ }^{30}$ Notwithstanding the obvious differences between this procedure and an airway endoscopy, Moerman et al. showed that TCI remifentanil resulted in a reduction in the doses of propofol and a lower incidence of apnea and respiratory depression compared with a manually controlled infusion of remifentanil. Cafiero et al. used mean target effect-site concentrations of $2.0(1.0) \mu \mathrm{g} \cdot \mathrm{mL}^{-1}$ of propofol and $3.2(0.3) \mathrm{ng} \cdot \mathrm{mL}^{-1}$ of remifentanil in their case series of 20 oral AFOIs. Surprisingly, they reported coughing in $60 \%$ of patients and increases in heart rate and blood pressure of $22 \%$ and $28 \%$, respectively, but $85 \%$ of patients had no recall of the procedure. ${ }^{16}$

Three studies have looked at the use of remifentanil required for AFOI in the absence of any other sedatives and without application of local anesthetic to the larynx. ${ }^{12,35,36}$ Under these conditions, Vennila et al. found that the mean effect-site concentrations of remifentanil required for fibreoptic endoscopy and railroading of the tracheal tube were $6.3 \mathrm{ng} \cdot \mathrm{mL}^{-1}$ and $8.06 \mathrm{ng} \cdot \mathrm{mL}^{-1}$, respectively. Despite the very high concentrations of remifentanil used in their study, it is interesting to point out that mild coughing during tracheal intubation was still found in 15 of the 20 patients, and 13 patients reported mild to moderate discomfort. $^{35}$ There were no reported incidences of adverse events, specifically, desaturation to $<90 \%$, although the authors did not report the respiratory rates during the procedure. In stark comparison, Zhang et al. found that a mean effect-site concentration of remifentanil of only 3.74 $( \pm 0.31) \mathrm{ng} \cdot \mathrm{mL}^{-1}$ was all that was necessary for AFOI without laryngeal topicalization. All their patients reported the procedure to be "acceptable"; however, the incidence of coughing and quantification of discomfort were not reported. ${ }^{12}$ Vennila et al. went on to suggest that a limitation of their study was that their patient population were all of young age (mean age 34) with few comorbidities (American Society of Anesthesiologists grade I-II).

Mingo et al. had previously described the use of remifentanil by simple infusion for AFOI in 24 patients, similarly with topical anesthesia limited to the nasal 
mucosa. $^{36}$ In their study, the dose ranged from 0.2$0.5 \mu \mathrm{g} \cdot \mathrm{kg}^{-1} \cdot \mathrm{min}^{-1}$, and the mean time from starting remifentanil to intubation was $12.5 \mathrm{~min}$, suggesting that the effect-site concentration range would likely have exceeded those of Zhang et al. ${ }^{12}$ and (at the highest rates) those of Vennila et al..$^{35}$ In three of the 24 patients, the respiratory rate fell to $<8$ breaths. $\min ^{-1}$ and the lowest rate recorded was 2 breaths $\cdot \min ^{-1}$. The patient population in their study was older (mean age 58) and mainly American Society of Anesthesiologists categories II and III.

\section{Dexmedetomidine}

For many years, the alpha 2 -adrenoceptor agonist, clonidine, has been widely used for its sedative, analgesic, and sympatholytic properties in both perioperative and critical care. Locus ceruleus $\alpha_{2}$ receptors mediate sedative properties while spinal alpha ${ }_{2}$ receptors mediate analgesic effects. ${ }^{37,38}$ Post-synaptic alpha ${ }_{2}$ receptors in the central nervous system and presynaptic alpha ${ }_{2}$ receptors in the peripheral nervous system mediate the cardiovascular effects of $\alpha_{2}$ agonists. Inhibition of noradrenaline release, bradycardia, and reduced cardiac output usually result in hypotension; however, $\alpha_{2}$ receptors located directly on vascular tissue cause vasoconstriction which can result in hypertension secondary to the use of large bolus doses of $\alpha_{2}$ agonists. ${ }^{39}$ The use of clonidine to facilitate AFOI was described in 2002 by Kulka et al., but since it was combined with clorazepate, propofol, and sufentanil, very little can be said of its usefulness. ${ }^{40}$

Dexmedetomidine, which has found favour for sedation in critical care, has a shorter half-life and eightfold greater selectivity for $\alpha_{2}$ over $\alpha_{1}$ receptors than clonidine. It has been enthusiastically advocated for AFOI on the grounds of its ability to produce profound sedation without causing the respiratory depression associated with other anxiolytic-hypnotic drugs and opioids. When respiratory compromise is seen, it occurs as a result of profound oversedation following very large initial bolus doses. ${ }^{41}$ In one study, healthy volunteers were sedated to the degree that they were unresponsive to shaking and shouting, but they were still able to maintain a spontaneous airway. ${ }^{38}$ Anterograde amnesia occurs with deeper levels of sedation, while a preserved level of cooperation is seen in otherwise very sleepy-looking patients. The antisialagogue and moderate analgesic properties of dexmedetomidine have been cited as other advantages. ${ }^{41,42}$

We identified 19 articles, five RCTs ${ }^{13,29,43-45}$ and 14 case reports and case series ${ }^{46-59}$ describing the use of dexmedetomidine for AFOI, usually as the sole agent but occasionally in combination with midazolam ${ }^{43}$ or ketamine. ${ }^{60}$ Although a TCI system for dexmedetomidine has been described for awake intubation, ${ }^{47}$ it is generally administered as a slow bolus (usually $1 \mu \mathrm{g} \cdot \mathrm{kg}^{-1}$ over 10-20 min) to avoid peak-dose hypertension (which may exacerbate a bradycardia-related fall in cardiac output) followed by an infusion (usually of $\left.0.1-0.7 \mu \mathrm{g} \cdot \mathrm{kg}^{-1} \cdot \mathrm{hr}^{-1}\right){ }^{29,43-45}$

Level 1 evidence for the efficacy and safety of dexmedetomidine for AFOI is provided by five RCTs. Tsai et al. randomized 40 patients needing AFOI to either dexmedetomidine $\left(1.0 \mu \mathrm{g} \cdot \mathrm{kg}^{-1}\right)$ or propofol TCI (effect-site concentration $3.6 \mu \mathrm{g} \cdot \mathrm{mL}^{-1}$ ) (see above and Table 2 ). Both drugs provided satisfactory intubating conditions; however, patients in the dexmedetomidine (DEX) group had less discomfort, heart rate changes, and episodes of airway obstruction $^{13}$. Hagberg et al. randomized 30 patients with "expected difficult airways" to either a dexmedetomidine bolus of $0.4 \mu \mathrm{g} \cdot \mathrm{kg}^{-1}$ followed by an infusion at a rate of $0.7 \mu \mathrm{g} \cdot \mathrm{kg}^{-1} \cdot \mathrm{hr}^{-1}$ or a remifentanil bolus $0.75 \mu \mathrm{g} \cdot \mathrm{kg}^{-1}$ followed by an infusion at a rate of $0.075 \mu \mathrm{g} \cdot \mathrm{kg}^{-1} \cdot \mathrm{min}^{-1}{ }^{29}$ There were no differences in recall or hemodynamic stability between the two groups; however, the DEX group required more attempts at intubation (first attempt success rates $38 \%$ in the dexmedetomidine and $76 \%$ in the remifentanil group), while mean oxygen saturation levels were lower in the remifentanil group. Interestingly, the sedation scores were lower in the DEX group, which may suggest that the smaller initial bolus of dexmedetomidine used in this study may have lacked efficacy in comparison with the doses used in other studies. This may be a contributing factor to the higher number of attempts at intubation in the DEX group.

Bergese et al. randomized 55 patients requiring AFOI to receive either dexmedetomidine and midazolam (DEXMDZ) or midazolam only (MDZ). Despite hemodynamic effects and intubating conditions being similar between groups, DEX-MDZ patients were significantly calmer and more cooperative during AFOI, and they had fewer adverse reactions during AFOI than the MDZ patients. ${ }^{43}$ They were also more satisfied with the AFOI $(P<0.001)$ than the midazolam-only patients. In another study by the same group, 105 patients requiring AFOI were randomized to either dexmedetomidine or a "placebo" with rescue midazolam as required to achieve a Ramsay sedation score of 2 prior to attempting oral or nasal intubation (mean doses $1.07 \mathrm{mg}$ and $2.85 \mathrm{mg}$ of rescue midazolam in the dexmedetomidine and "placebo" groups, respectively). In the placebo group, $28 \%$ of patients developed significant hypertension and $24 \%$ developed significant tachycardia, while in the DEX group, $27 \%$ of patients became hypotensive and heart rates were said to have fallen significantly. ${ }^{44}$

It is interesting to point out that the authors chose to compare DEX with midazolam only sedation, which is commonly used in combination with an opioid for AFOI. Consequently, it is not surprising that patients in the midazolam only group in both RCTs had hypertension and tachycardia and were less cooperative and not as satisfied with the experience. 
These findings are supported by a study by Chu et al. who randomized 30 oral cancer patients with limited mouth opening to either dexmedetomidine or fentanyl (both $\left.1 \mu \mathrm{g} \cdot \mathrm{kg}^{-1}\right)$. The DEX group had better intubating conditions and patient tolerance of the procedure and less hemodynamic response to intubation with minimal adverse effects. ${ }^{45}$ Again, it is not surprising that this study found in favour of the hemodynamic outcomes of dexmedetomidine when the dose of fentanyl used in the comparator group was less than that used by Ovassapian et al. in combination with midazolam $\left(1.56 \mu \mathrm{g} \cdot \mathrm{kg}^{-1}\right.$ and $0.12 \mathrm{mg} \cdot \mathrm{kg}^{-1}$, respectively). When they reported increases of $\geq 20 \mathrm{mmHg}$ in mean arterial pressure and $\geq 20$ beats $\cdot \min ^{-1}$ in heart rate in $30 \%$ of their patients. ${ }^{2}$

It could be argued that the relatively long loading time of the first dose of dexmedetomidine may be a disadvantage; however, the main adverse effects reported with its use are bradycardia and hypotension. ${ }^{39,50}$ Although the former generally doesn't appear to be a significant problem (possibly due to the concurrent use of glycopyrrolate in most studies), hypotension may be, particularly following subsequent induction of general anesthesia. In 13/20 patients, Avitsian et al. reported marked post-induction hypotension that responded to boluses of phenylephrine or ephedrine in all but one case in which the administration of adrenaline was necessary. ${ }^{51}$

The safe respiratory profile of dexmedetomidine has been borne out by reports describing its use in patients with raised intracranial pressure at risk from hypoventilation ${ }^{52}$ and in obstetrics with minimal adverse neonatal sequelae. ${ }^{53,54}$ The ability to produce a deeply sedated state while maintaining a safe degree of respiratory function has also allowed it to be successfully used in children and uncooperative adults. ${ }^{55,56}$ Nevertheless, the real advantage of a sedative that spares respiratory function may become apparent when the clinician is presented with patients already in or at risk of airway obstruction and/or respiratory failure; yet (not surprisingly), to date, there have been only limited case series dealing with such cases. ${ }^{46,49,50}$ Boyd and Sutter reported the safe use of dexmedetomidine for AFOI in two patients with severe submandibular abscesses and impending oropharyngeal obstruction, ${ }^{49}$ while Abdelmalak et al. reported its safe use in three patients with impending respiratory failure. ${ }^{50}$

In cases of critical airway obstruction, avoidance of drugs that depress both conscious level and ventilatory drive, as alluded to above, is recommended. While no one would argue that this recommendation applies to any agent that acts by modulating the $\mathrm{GABA}_{\mathrm{A}}$ receptor, there is little evidence that sedation with an agent that depresses ventilation but not level of consciousness (remifentanil) or vice versa (dexmedetomidine) is more dangerous than conducting AFOI with LA alone. Topical anesthesia in patients with critical airway obstruction can be difficult to achieve, ${ }^{62}$ and though a rarity, inadequate anesthesia of the larynx or even the application of topical anesthesia itself can precipitate total airway obstruction ${ }^{63-65}$ Although there has been a recent description of the use of dexmedetomidine with no use of LA at all, ${ }^{57}$ there is generally more evidence supporting the safe use of remifentanil in this fashion, at least in the context of patients without critical airway obstruction.

\section{Other sedatives and novel drug combinations}

Another drug that merits a discussion is the use of ketamine for AFOI. In a well-designed RCT by Belda et al., 70 morbidly obese patients requiring AFOI were randomized to three groups; TCI remifentanil, ketamine $\left(0.3 \mathrm{mg} \cdot \mathrm{kg}^{-1}\right.$ $i v)$, or remifentanil and ketamine for sedation. ${ }^{66}$ All patients were premedicated with midazolam $(2 \mathrm{mg})$. The authors found that the addition of ketamine to remifentanil increased the incidence of intense cough from $12 \%$ to $44 \%$ but made no difference to the incidence of desaturation, and they concluded that the addition of ketamine to remifentanil offered no advantage. The ketamine only group had an unacceptably high incidence of intense cough $(60 \%)$, agitation $(15 \%)$, inadequate level of sedation $(10 \%)$, and uncomfortable recall $(60 \%)$, and the authors suggested that ketamine alone is not an adequate sedation strategy for AFOI. A previous case report had described the addition of ketamine to dexmedetomidine for AFOI, and its effects in countering the bradycardia associated with the latter may amount to a better use for this combination. ${ }^{60}$

\section{Discussion}

The need for conscious sedation during an AFOI is now widely accepted. Kopman et al. highlighted its advantages as early as 1975 in a review of 267 awake intubations. ${ }^{67}$ Nevertheless, the quest for the ideal drug for conscious sedation for an AFOI is an ongoing process. More sparing use of LA can be partially compensated with opioids, but even when pain and discomfort are largely eliminated, there may still be significant psychological obstacles to the tolerance of the procedure. It helps to have excellent rapport and a subject who has complete confidence in the procedure, but these may not always be enough, even in well-informed and highly motivated individuals. ${ }^{68}$ A proportion of qualified practitioners, themselves undergoing AFOI on teaching courses, still report being uncomfortable and/or anxious, and there may be significant hemodynamic changes when no anxiolytic agent is used. ${ }^{69,70}$ 
The last decade has seen the practice of conscious sedation revolutionized, not only by the introduction of drugs with unique pharmacokinetic properties, such as propofol, remifentanil, and dexmedetomidine, but also by the introduction of target-controlled drug infusion systems that allow for easy titration and maintenance of steady state drug levels. The relative advantages and disadvantages of three commonly used drugs, propofol, remifentanil, and dexmedetomidine, are summarized in Table 4.

There is sufficient level 1 evidence in the form of welldesigned RCTs to support the statement that propofol is not very effective as a primary sedative agent for AFOI. Propofol used alone or in combination with midazolam is associated with more coughing when compared with remifentanil and dexmedetomidine, and this can translate into poor intubating conditions. Evidence suggests an increased risk of oversedation and subsequent airway obstruction associated with the use of propofol when compared with remifentanil and dexmedetomidine. The main advantage of propofol seems to be a low incidence of recall, and it is this property that makes it an attractive adjunct to drugs such as remifentanil. Although, most of the studies have used propofol as a TCI, there is lack of evidence to suggest that it is superior to a fixed-rate infusion. Furthermore, there is no consensus on the ideal dose range for propofol use in AFOI. It is clear, however, that use of high doses of propofol to improve intubating conditions is associated with an increasing incidence of oversedation and airway obstruction.

The two drugs that stand out in terms of increasing popularity and growing evidence to support their use are remifentanil, an ultra-short-acting noncumulative opioid, and dexmedetomidine, a highly selective $\alpha_{2}$-agonist. While each drug has certain unique pharmacological properties that make it attractive for use as conscious sedation for AFOI, it is interesting to point out that the same properties may also result in the drawbacks associated with their use.

Several well-designed RCTs support the use of remifentanil for AFOI, especially as a TCI. Remifentanil was found to provide better intubating conditions when compared with propofol in three well-designed RCTs. Despite its use being associated with a high incidence of recall, it is well tolerated by patients, which is indicated by the high patient satisfaction scores reported in most studies. The incidence of recall can be decreased by concomitant use of midazolam and /or propofol; however, their addition can potentiate the other disadvantage associated with remifentanil, i.e., respiratory depression, which is generally seen as a dose-related decrease in respiratory rate and minute ventilation. The question that needs to be asked is whether recall of events in itself is a disadvantage, particularly if the patient does not perceive the recalled procedure as unpleasant. Data suggest that most patients are not unduly distressed by recall of events; however, this may be an issue in a patient who is extremely anxious and desires a degree of amnesia.

There is consensus on the dose range required for TCI remifentanil; an effect-site concentration in the range of 3-5 $\mathrm{ng} \cdot \mathrm{mL}^{-1}$ will produce the desired conditions when used in conjunction with midazolam 1-2 $\mathrm{mg}$ or when combined with a small effect-site concentration of propofol $\left(<1.0 \mu \mathrm{g} \cdot \mathrm{mL}^{-1}\right)$. The use of higher doses of remifentanil (5-8 ng. $\left.\mathrm{mL}^{-1}\right)$ with a view to avoid combination therapy and minimize the topical application of local anesthetic can be associated with hypoxia and respiratory depression, and this technique is unlikely to be applicable to the wider population.

It is the authors' practice to use TCI remifentanil at a starting concentration of $3 \mathrm{ng} \cdot \mathrm{mL}^{-1}$ and TCI propofol at 0.5 $0.8 \mu \mathrm{g} \cdot \mathrm{mL}^{-1}$ for AFOI. Once the plasma and effect-site concentrations have achieved equilibrium, the decision to titrate remifentanil and/or propofol will depend on the patient. In a majority of patients, TCI propofol at $0.8 \mu \mathrm{g} \cdot \mathrm{mL}^{-1}$ provides a reasonable degree of amnesia, and remifentanil is titrated up to $3-5 \mathrm{ng} \cdot \mathrm{mL}^{-1}$ to achieve the desired level of sedation. In anxious patients where recall may be perceived as unpleasant, remifentanil may be set to $3 \mathrm{ng} \cdot \mathrm{mL}^{-1}$, while the propofol is titrated to $1.0-1.5 \mu \mathrm{g} \cdot \mathrm{mL}^{-1}$

Table 4 Properties and adverse effects of remifentanil, dexmedetomidine, and propofol when used for conscious sedation for AFOI

\begin{tabular}{llll}
\hline & Remifentanil & Dexmedetomidine & Propofol \\
\hline Patient satisfaction & High $^{10-12,28}$ & High $^{13,43-45}$ & High $^{9-11,13}$ \\
Recall of events & High $^{10-12,25,28,29}$ & Variable $^{29,45,48,50}$ & Low $^{10-13}$ \\
Risk of oversedation & Low $^{10-12,29,33,35,36}$ & Low $^{13,29,38,55,56}$ & High $^{11-13}$ \\
Airway obstruction & $\mathrm{No}^{10,25,27}$ & $\mathrm{No}^{13,27}$ & Yes $^{11-13}$ \\
Bradycardia & $\mathrm{No}^{10-12,25,36}$ & Yes $^{44,50,61}$ & $\mathrm{No}^{9-13}$ \\
Hypotension & $\mathrm{No}^{10-12,25,36}$ & Yes $^{44,50,51,61}$ & $\mathrm{No}^{9-13}$ \\
Respiratory depression & $\mathrm{Yes}^{25,28,29,36}$ & $\mathrm{No}^{13,29,38,46,49,50,52}$ & $\mathrm{No}^{8,10-13}$ \\
Coughing & $\mathrm{No}^{10,25}$ & Variable $^{13,45,48}$ & Yes $^{10,11,13}$ \\
\hline
\end{tabular}

AFOI = awake fibreoptic intubation 
as required. This latter approach may also be required when dealing with chronic pain patients on high doses of opioid in whom remifentanil, even at concentrations of $7-8 \mathrm{ng} \cdot \mathrm{mL}^{-1}$, may be ineffective and propofol is the more desirable drug.

It is also our practice to ensure meticulous application of LA despite the more forgiving nature of modern sedatives. This skill may be of great use when faced with the need to perform an AFOI in a patient with airway obstruction.

The other drug that is gaining popularity is dexmedetomidine, as it creates a state of "cooperative sedation" from which the patient is easily rousable, while its antisialagogue effect contributes to good conditions for AFOI. Level 1 evidence supports its use on the basis of good intubating conditions, its tolerance by patients, and its high reported patient satisfaction scores. Nevertheless, there is lack of current evidence to suggest that it is superior to either propofol or remifentanil as sedation for AFOI, since a degree of bias must be implicit in all of the RCTs involving dexmedetomidine to date. There is good evidence to suggest that a $0.7-1.0 \mu \mathrm{g} \cdot \mathrm{kg}^{-1}$ bolus over ten minutes followed by a $0.3-0.7 \mu \mathrm{g} \cdot \mathrm{kg}^{-1} \cdot \mathrm{hr}^{-1}$ infusion will create the conditions required for AFOI with minimal side effects.

The large number of case reports and case series certainly support the premise that dexmedetomidine is a promising drug with little effect on respiration and side effects (such as hypotension and bradycardia) which are occasional and can be treated.

The use of sedation in patients with impending airway obstruction is a controversial issue. Avoidance of drugs that depress conscious level and ventilatory drive is usually recommended; however, application of topical anesthesia has been reported to precipitate complete airway obstruction. ${ }^{63,65}$ Theoretically, remifentanil should not affect a patient's level of consciousness or airway patency and may be of benefit in patients where extreme anxiety or distress with resultant tachypnea and tachycardia may compound the problem. Nevertheless, hypoventilation associated with its use can compromise the airway, especially in this clinical setting, and low doses of remifentanil would be used only with extreme caution in these circumstances. There are no case reports or series to support the use of remifentanil in this context, which is not surprising given the rarity of these clinical situations and the declining popularity of the "case report". There is some evidence in case reports to support the use of dexmedetomidine in this situation. At present, no recommendations can be made, and a clinician will need to use individual experience and judgement on a case by case basis.

It is important to realize that anesthesiologists experienced in AFOI may achieve good results with any of the abovementioned drugs; however, there is a lack of data to suggest which drug is more suitable in the hands of those who seldom perform an AFOI. One of the main limitations of this review is the paucity of level 1 evidence in the form of well-designed randomized controlled studies. We identified 14 RCTs over a period extending more than 30 years. Most of the available evidence is in the form of observational studies and case series or isolated case reports. This is probably a reflection of the fact that RCTs are difficult to conduct given the difficulties involved in recruiting from a small and highly select patient population and the need for anesthesiologists who are experienced in performing this procedure. There is a definite need for a large welldesigned multicentre trial that may finally provide the much needed data.

Competing interests None declared.

\section{References}

1. Ovassapian A, Yelich SJ, Dykes MH, Brunner EE. Fiberoptic nasotracheal intubation - incidence and causes of failure. Anesth Analg 1983; 62: 692-5.

2. Ovassapian A, Yelich SJ, Dykes MH, Brunner EE. Blood pressure and heart rate changes during awake fibreoptic nasotracheal intubation. Anesth Analg 1983; 62: 951-4.

3. Ovassapian A, Krejcie TC, Yelich SJ, Dykes MH. Awake fibreoptic intubation in the patient at high risk of aspiration. $\mathrm{Br} \mathrm{J}$ Anaesth 1989; 62: 13-6.

4. Sidhu VS, Whitehead EM, Ainsworth QP, Smith M, Calder I. A technique of awake fibreoptic intubation. Experience in patients with cervical spine disease. Anaesthesia 1993; 48: 910-3.

5. Reasoner DK, Warner DS, Todd MM, Hunt SW, Kirchner J. A comparison of anesthetic techniques for awake intubation in neurosurgical patients. J Neurosurg Anesthesiol 1995; 7: 94-9.

6. Joo HS, Kapoor S, Rose DK, Naik VN. The intubating laryngeal mask airway after induction of general anesthesia versus awake fiberoptic intubation in patients with difficult airways. Anesth Analg 2001; 92: 1342-6.

7. Lee JH, Han SW, Kim $Y Y$, Yeom $K W$. Sedation and hemodynamic stability during fiberoptic awake nasotracheal intubation: comparison between propofol infusion and intravenous boluses of fentanyl and midazolam (Korean). Korean J Anesthesiol 1997; 33: 741-9.

8. Huitink JM, Balm AJ, Keijzer C, Buitelaar DR. Awake fibrecapnic intubation in head and neck cancer patients with difficult airways: new findings and refinements to the technique. Anaesthesia $2007 ; 62:$ 214-9.

9. Neidhart $G$, Bremerich DH, Kessler P. Fiberoptic intubation during remifentanil propofol sedation (German). Anaesthesist 2001; 50: 242-7.

10. Rai MR, Parry TM, Dombrovskis A, Warner OJ. Remifentanil target-controlled infusion vs propofol target-controlled infusion for conscious sedation for awake fibreoptic intubation: a doubleblind randomised controlled trial. $\mathrm{Br} \mathrm{J}$ Anaesth 2008; 100: 125-30.

11. Lallo A, Billard V, Bourgain JL. A comparison of propofol and remifentanil target-controlled infusions to facilitate fiberoptic nasotracheal intubation. Anesth Analg 2009; 108: 852-7.

12. Zhang $X$, He $W, W u X$, Zhou $X$, Huang $W$, Feng $X$. TCI remifentanil vs. TCI propofol for awake fiber-optic intubation with limited topical anesthesia. Int J Clin Pharmacol Ther 2012; 50: $10-6$. 
13. Tsai CJ, Chu KS, Chen TI, Lu DV, Wang HM, Lu IC. A comparison of the effectiveness of dexmedetomidine versus propofol target-controlled infusion for sedation during fibreoptic nasotracheal intubation. Anaesthesia 2010; 65: 254-9.

14. Donaldson AB, Meyer-Witting M, Roux A. Awake fibreoptic intubation under remifentanil and propofol target-controlled infusion. Anaesth Intensive Care 2002; 30: 93-5.

15. La Colla L, La Colla G, Albertin A, Poli D, Baruffaldi Preis FW, Mangano A. The use of propofol and remifentanil for the anaesthetic management of a super-obese patient. Anaesthesia 2007; 62: 842-5.

16. Cafiero $T$, Esposito $F$, Fraioli $G$, et al. Remifentanil-TCI and propofol-TCI for conscious sedation during fibreoptic intubation in the acromegalic patient. Eur J Anaesthesiol 2008; 25: 670-4.

17. Randell T, Valli H, Lindgren L. Effects of alfentanil on the responses to awake fiberoptic nasotracheal intubation. Acta Anaesthesiol Scand 1990; 34: 59-62.

18. Bailey PL, Pace NL, Ashburn MA, Moll JW, East KA, Stanley TH. Frequent hypoxemia and apnea after sedation with midazolam and fentanyl. Anesthesiology 1990; 73: 826-30.

19. Brock-Utne JG, Winning TJ, Rubin J, Kingston HG. Laryngeal incompetence during neuroleptanalgesia in combination with diazepam. Br J Anaesth 1976; 48: 699-701.

20. Kapila A, Glass PS, Jacobs JR, et al. Measured context-sensitive half-times of remifentanil and alfentanil. Anesthesiology 1995; 83: 968-75.

21. Glass PS, Hardman D, Kamiyama $Y$, et al. Preliminary pharmacokinetics and pharmacodynamics of an ultra-short-acting opioid: remifentanil (G187084B). Anesth Analg 1993; 77: 1031-40.

22. Burkle H, Dunbar S, Van Aken H. Remifentanil: a novel, short acting, mu-opioid. Anesth Analg 1996; 83: 646-51.

23. Minto CF, Schnider TW, Shafer SL. Pharmacokinetics and pharmacodynamics of remifentanil. II Model application. Anesthesiology 1997; 86: 24-33.

24. Minto CF, Schnider TW, Egan TD, et al. Influence of age and gender on the pharmacokinetics and pharmacodynamics of remifentanil. I Model development. Anesthesiology 1997; 86: 10-23.

25. Machata AM, Gonano C, Holzer A, et al. Awake nasotracheal fiberoptic intubation: patient comfort, intubating conditions, and hemodynamic stability during conscious sedation with remifentanil. Anesth Analg 2003; 97: 904-8.

26. Reusche MD, Egan TD. Remifentanil for conscious sedation and analgesia during awake fiberoptic tracheal intubation: a case report with pharmacokinetic simulations. J Clin Anesth 1999; 11: 64-8.

27. Puchner $W$, Obwegeser J, Puhringer FK. Use of remifentanil for awake fiberoptic intubation in a morbidly obese patient with severe inflammation of the neck. Acta Anaesthesiol Scand 2002; 46: 473-6.

28. Puchner W, Egger P, Puhringer F, Lockinger A, Obwegeser J, Gombotz $H$. Evaluation of remifentanil as single drug for awake fiberoptic intubation. Acta Anaesthesiol Scand 2002; 46: 350-4.

29. Hagberg CA, Lam NC, Abramson SI, Vahdat K, Craig J. Dexmedetomidine vs. remifentanil for sedation in awake intubations. A randomized, double-blind trial. Anesthesiology 2008; 109: A14 (abstract).

30. Moerman AT, Herregods LL, De Vos MM, Mortier EP, Struys $M M$. Manual versus target-controlled infusion remifentanil administration in spontaneously breathing patients. Anesth Analg 2009; 108: 828-34.

31. De Castro V, Godet G, Mencia M, Raux M, Coriat P. Targetcontrolled infusion for remifentanil in vascular patients improves hemodynamics and decreases remifentanil requirement. Anesth Analg 2003; 96: 33-8.

32. Olofsen E, Boom M, Nieuwenhuijs D, et al. Modeling the nonsteady state respiratory effects of remifentanil in awake and propofol-sedated healthy volunteers. Anesthesiology 2010; 112: 1382-95.

33. Song JW, Kwak YL, Lee JW, Chang CH, Kim HS, Shim YH. The optimal effect site concentration of remifentanil in combination with intravenous midazolam and topical lidocaine for awake fibreoptic nasotracheal intubation in patients undergoing cervical spine surgery. Minerva Anestesiol 2012; 78: 521-6.

34. Avramov $M$, Smith I, White PF. Interactions between midazolam and remifentanil during monitored anesthesia care. Anesthesiology 1996; 85: 1283-9.

35. Vennila $R$, Hall A, Ali $M$, Bhuiyan $N$, Pirotta D, Raw DA. Remifentanil as single agent to facilitate awake fibreoptic intubation in the absence of premedication. Anaesthesia 2011; 66: 368-72.

36. Mingo OH, Ashpole KJ, Irving CJ, Rucklidge $M W$. Remifentanil sedation for awake fibreoptic intubation with limited application of local anaesthetic in patients for elective head and neck surgery. Anaesthesia 2008; 63: 1065-9.

37. Scheinin M, Schwinn DA. The locus coeruleus. Site of hypnotic actions of alpha 2-adrenoceptor agonists? Anesthesiology 1992; 76: 873-5.

38. Ebert TJ, Hall JE, Barney JA, Uhrich TD, Colinco MD. The effect of increasing plasma concentrations of dexmedetomidine in humans. Anesthesiology 2000; 93: 382-94.

39. Venn RM, Bradshaw CJ, Spencer R, et al. Preliminary UK experience of dexmedetomidine, a novel agent for postoperative sedation in the intensive care unit. Anaesthesia 1999; 54: 1136-42.

40. Kulka PJ, Tryba M, Zenz M. Difficult airway management in a patient with severe aortic stenosis, coronary artery disease, and heart failure. J Clin Anesth 2002; 14: 150-3.

41. Belleville JP, Ward DS, Bloor BC, Maze M. Effects of intravenous dexmedetomidine in humans. I. Sedation, ventilation, and metabolic rate. Anesthesiology 1992; 77: 1125-33.

42. Hall JE, Uhrich TD, Barney JA, Arain SR, Ebert TJ. Sedative, amnestic, and analgesic properties of small-dose dexmedetomidine infusions. Anesth Analg 2000; 90: 699-705.

43. Bergese SD, Bender SP, McSweeney TD, Fernandez $S$, Dzwonczyk $R$, Sage K. A comparative study of dexmedetomidine with midazolam and midazolam alone for sedation during elective awake fiberoptic intubation. J Clin Anesth 2010; 22: 35-40.

44. Bergese SD, Candiotti K, Zura A, Bokesch PM, Bekker AY. Dexmedetomidine for sedation during elective fiberoptic intubation: a multicenter trial. Anesthesiology 2008; 109: A186 (abstract).

45. Chu KS, Wang FY, Hsu HT, Lu IC, Wang HM, Tsai CJ. The effectiveness of dexmedetomidine infusion for sedating oral cancer patients undergoing awake fibreoptic nasal intubation. Eur J Anaesthesiol 2010; 27: 36-40.

46. Bergese SD, Khabiri B, Roberts WD, Howie MB, McSweeney TD, Gerhardt MA. Dexmedetomidine for conscious sedation in difficult awake fiberoptic intubation cases. J Clin Anesth 2007; 19: $141-4$

47. Kunisawa T, Nagashima M, Hanada S, Suzuki A, Takahata O, Iwasaki $H$. Awake intubation under sedation using target-controlled infusion of dexmedetomidine: five case reports. J Anesth 2010; 24: 789-92.

48. Grant SA, Breslin DS, MacLeod DB, Gleason D, Martin G. Dexmedetomidine infusion for sedation during fiberoptic intubation: a report of three cases. J Clin Anesth 2004; 16: 124-6.

49. Boyd BC, Sutter SJ. Dexmedetomidine sedation for awake fiberoptic intubation of patients with difficult airways due to severe odontogenic cervicofacial infections. J Oral Maxillofac Surg 2011; 69: 1608-12.

50. Abdelmalak B, Makary L, Hoban J, Doyle DJ. Dexmedetomidine as sole sedative for awake intubation in management of the critical airway. J Clin Anesth 2007; 19: 370-3. 
51. Avitsian R, Lin J, Lotto M, Ebrahim Z. Dexmedetomidine and awake fiberoptic intubation for possible cervical spine myelopathy: a clinical series. J Neurosurg Anesthesiol 2005; 17: 97-9.

52. Sriganesh K, Ramesh VJ, Veena S, Chandramouli BA. Dexmedetomidine for awake fibreoptic intubation and awake selfpositioning in a patient with a critically located cervical lesion for surgical removal of infra-tentorial tumour. Anaesthesia 2010; 65: 949-51.

53. Neumann MM, Davio MB, Macknet MR, Applegate RL 2nd. Dexmedetomidine for awake fiberoptic intubation in a parturient with spinal muscular atrophy type III for cesarean delivery. Int J Obstet Anesth 2009; 18: 403-7.

54. Shah TH, Badve MS, Olajide KO, Skorupan HM, Waters JH, Vallejo $M C$. Dexmedetomidine for an awake fiber-optic intubation of a parturient with Klippel-Feil syndrome, type I Arnold Chiari malformation and status post released tethered spinal cord presenting for repeat cesarean section. Clinics Pract 2011; 1: e57.

55. Jooste EH, Ohkawa S, Sun LS. Fiberoptic intubation with dexmedetomidine in two children with spinal cord impingements. Anesth Analg 2005; 101: 1248.

56. Stamenkovic DM, Hassid M. Dexmedetomidine for fiberoptic intubation of a patient with severe mental retardation and atlantoaxial instability. Acta Anaesthesiol Scand 2006; 50: 1314-5.

57. Madhere M, Vangura D, Saidov A. Dexmedetomidine as sole agent for awake fiberoptic intubation in a patient with local anesthetic allergy. J Anesth 2011; 25: 592-4.

58. Maroof M, Khan RM, Jain D, Ashraf M. Dexmedetomidine is a useful adjunct for awake intubation. Can J Anesth 2005; 52: 776-7.

59. Cooper L, Samson R, Gallagher C, Barron M, Candiotti K. Dexmedetomidine provides excellent sedation for elective awake fiberoptic intubation. Anesthesiology 2005; 103: A1449 (abstract).

60. Scher CS, Gitlin MC. Dexmedetomidine and low-dose ketamine provide adequate sedation for awake fibreoptic intubation. Can $\mathrm{J}$ Anesth 2003; 50: 607-10.
61. Unger RJ, Gallagher CJ. Dexmedetomidine sedation for awake fibreoptic intubation. Semin Anesth Perioper Med Pain 2006; 25: 65-70.

62. Patel A, Pearce A. Progress in management of the obstructed airway. Anaesthesia 2011; 66(Suppl 2): 93-100.

63. Shaw IC, Welchew EA, Harrison BJ, Michael S. Complete airway obstruction during awake fibreoptic intubation. Anaesthesia 1997; 52: 582-5.

64. McGuire G, El-Beheiry H. Complete upper airway obstruction during awake fibreoptic intubation in patients with unstable cervical spine fractures. Can J Anesth 1999; 46: 176-8.

65. Ho AM, Chung DC, To EW, Karmakar MK. Total airway obstruction during local anesthesia in a non-sedated patient with a compromised airway. Can J Anesth 2004; 51: 838-41.

66. Belda I, Cubas MG, Rivas E, Valero R, Martínez-Pallí G, Balust $J$. Remifentanil target controlled infusion (TCI) vs ketamine or ketamine in combination with remifentanil TCI for conscious sedation in awake fiberoptic intubation: a randomized controlled trial: 19AP1-5. Eur J Anaesthesiol 2011; 28: 226 (abstract).

67. Kopman AF, Wallman SB, Ross K, Surks SN. Awake endotracheal intubation: a review of 267 cases. Anesth Analg 1975; 54: 323-7.

68. Davis JL. Fiberoptic 'awake' nasal intubation: physiological and personal concepts. J Neurosci Nurs 1988; 20: 198-200.

69. Patil V, Barker GL, Harwood RJ, Woodall NM. Training course in local anaesthesia of the airway and fibreoptic intubation using course delegates as subjects. Br J Anaesth 2002; 89: 586-93.

70. Woodall NM, Harwood RJ, Barker GL. Complications of awake fibreoptic intubation without sedation in 200 healthy anaesthetists attending a training course. Br J Anaesth 2008; 100: 850-5.

71. Yeganeh $N$, Roshani B, Azizi B, Almasi A. Target-controlled infusion of remifentanil to provide analgesia for awake nasotracheal fiberoptic intubations in cervical trauma patients. J Trauma 2010; 69: 1185-90.

72. Sutherland $A D$, Williams RT. Cardiovascular responses and lidocaine absorption in fiberoptic-assisted awake intubation. Anesth Analg 1986; 65: 389-91. 